\title{
Research Studies on the Thrust of Special-Shaped Full-Sectional Cutterheads of Quasirectangular Shield
}

\author{
Yaohong Zhu, ${ }^{1,2}$ Jiawei Wang, ${ }^{3}$ Bayang Zhang, ${ }^{3}$ Xuqing Zhang, ${ }^{4}$ and Jue Zhu $\mathbb{D}^{3}$ \\ ${ }^{1}$ Collaborative Innovation Center of Coastal Urban Rail Transit, Ningbo University, Ningbo, Zhejiang 315211, China \\ ${ }^{2}$ Ningbo Rail Trainsit Group Co., Ltd., Ningbo, Zhejiang 315211, China \\ ${ }^{3}$ Key Laboratory of Impact and Safety Engineering Ministry of Education, Ningbo University, Ningbo, Zhejiang 315211, China \\ ${ }^{4}$ Ningbo Yonggong Technology Co., Ltd., Ningbo, Zhejiang 315211, China \\ Correspondence should be addressed to Jue Zhu; zhujue@nbu.edu.cn
}

Received 29 May 2020; Revised 17 December 2020; Accepted 6 March 2021; Published 2 April 2021

Academic Editor: Daniele Baraldi

Copyright $\odot 2021$ Yaohong Zhu et al. This is an open access article distributed under the Creative Commons Attribution License, which permits unrestricted use, distribution, and reproduction in any medium, provided the original work is properly cited.

\begin{abstract}
Thrust of shield cutters is the major parameter of tunnel construction and an important index for shield machine design. The thrust bearing resistance of a shield machine has a significant impact on its construction efficiency and safe operation. The use of quasirectangular shield not only can increase the space utilization rate but also avoid the deformation of the back soil when compared with a conventional circular or rectangular shield. In this paper, structural analysis of quasirectangular shield cutterhead is carried out and a corresponding mathematical thrust model is developed. Both the stress and displacement distributions of cutterhead are calculated. It is found that the stress value in most regions of the cutterhead is between $5 \mathrm{MPa}$ and $45 \mathrm{MPa}$. The maximum stress is $208.44 \mathrm{MPa}$, which is at the middle part of the rib and is below the yield limit. The maximum deformation is found in the center area of the chest plate, the value of which is also within the design requirement. In addition, a monitoring method suitable for quasirectangular shield is proposed. The appropriateness and reliability of the proposed monitoring method are demonstrated by the comparison between the numerical simulation and monitoring method.
\end{abstract}

\section{Introduction}

In recent years, the continuous development of urbanization leads to a high-speed construction of underground railways in China, particularly in medium and large cities [1-3]. However, in urban core areas, this requires to design new subway lines in the crowded shallow underground space. Therefore, the new construction scheme of underground tunnels is urgently needed.

Most of the tunnels can be excavated by using drilling, blasting, or tunneling boring machines (i.e., shield machines) [4]. The shield method is a mechanized construction method, which has been widely used in the construction process of underground tunnels. The operating principle of the method is to use the front cutterhead to excavate the soil and transport it out of the cave through the transport machinery, while the subsequent segment is compressed by jacks. Prefabricated concrete segments are utilized to form the overall structure of the tunnel [5]. The surrounding soil is supported by the shield shell and laying segments to prevent its collapse while the shield machine is operating.

Quasirectangular shield machine is a new type of singletunnel and double-track excavation shield machines. Compared with circular shield machines and DOT (doubleO-tube) shield machines, the quasirectangular shield machine improves space utilization and can avoid burdening soil on top of the shield machine. Compared with rectangular shield tunnel structures, the quasirectangular shield machine can avoid the problem such as easy to deform and the assembling difficulty. The cutterheads in most shield machines are subjected to large thrust during the excavation process. The thrust bearing capacity has a serious impact not only on the construction efficiency but also on the construction safety. Therefore, it is necessary to examine the thrust of the rectangular-shaped shield cutterhead.

Many studies were carried out to analyze the load and thrust of shield cutterhead in the last decade. Han et al. [6] analyzed the dynamic characteristics of the cutterhead load 
in the shield working period, in which the cutterhead load was approached as normal distribution and the thrust was assumed to depend on the penetration and uniaxial compressive strength of the surrounding rock. Zhang et al. [7] proposed an approximate method for calculating the loads acting on the cutterhead-ground interface of an earth pressure balance shield machine and developed the expressions of normal and tangential stresses acting on the tunneling interface between cutterhead and ground. Balci [8] and Dahl et al. [9] proposed a method to directly measure the service life of shield cutterhead and made some recommendations for the arrangement of cutterhead. Liu et al. [10] carried out an on-site monitoring analysis and performed a 3D finite element analysis on the mechanical behavior of shields during construction. Qi et al. (2019) analyzed the rock muck transfer process of shield cutterhead and thrust in the construction process. Many numerical studies have been conducted to simulate the cutterhead thrust and dynamic characteristics of shields [11-13]. Various methods were proposed to measure and record the working data of shield cutterhead [14-16].

\section{Cutterhead of Quasirectangular Shield Machine}

2.1. Structure of Quasirectangular Shield Machine. The quasirectangular shield machine was developed by Shanghai Tunnel Research Institute. Its main structure consists of the following components: two round cutterheads with a diameter of $6730 \mathrm{~mm}$ (red ones in Figure 1), an eccentric cutterhead system (the blue one in Figure 1), cutterhead driving system, dumping system, shell system, propulsion system, hydraulic system, electronic system, and so on. Figure 1 shows an actual quasirectangular shield machine.

\subsection{Cutting Principle of Quasirectangle Shield Machine.} The cutting section of this shield machine is similar to the combination of oval and rectangle. A new combined cutting method is adopted to cut the whole section completely. Two large X-shaped spoke cutterheads are distributed on each side of the cutting section, while the blue eccentric cutterhead is distributed in the center and staggered behind the large red cutterheads. The center-to-center distance of the two large cutterheads is smaller than their diameter. The rotating speeds of cutterheads are controlled by programs to maintain a $90^{\circ}$ phase difference to prevent collision between cutterheads. The arrangement of the eccentric cutterhead is for the uncut area where the large cutterheads cannot reach to achieve full-section cutting. Figures 2 and 3 show the arrangement and cutting trace of the cutterheads, respectively.

2.3. Analysis of Thrust. During its operation, the shield machine is subjected to a large front resistance and initially has a slow advancing speed. The jacking thrust applied by the propulsion system imposes on the tunnel face through the cutterheads. Therefore, the reaction force from the tunnel face can be regarded as the external load imposed on the

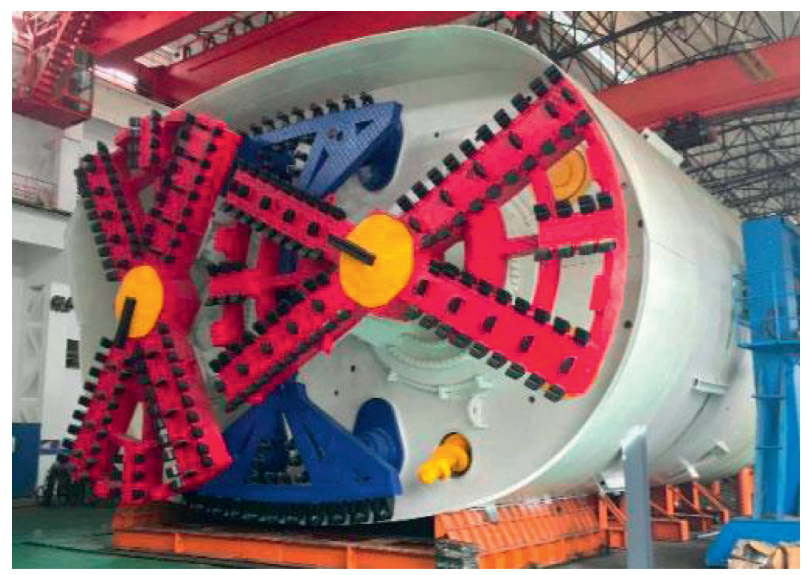

Figure 1: Actual quasirectangular shield machine.

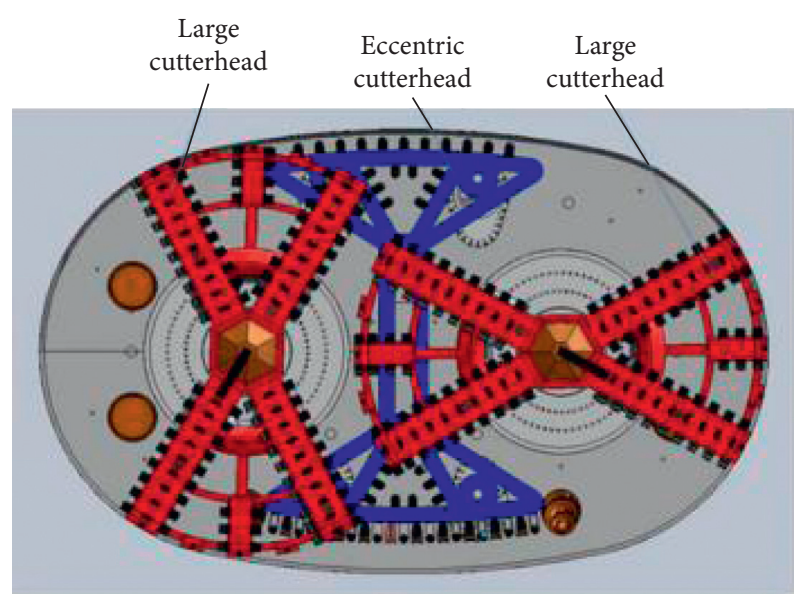

Figure 2: Arrangement of cutterheads.

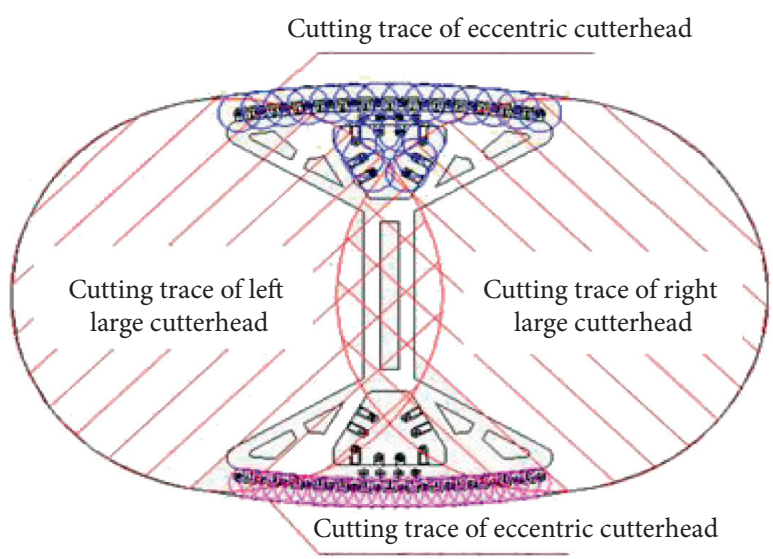

FIgURE 3: Cutting trace of cutterhead.

cutterheads, that is, the front thrust of cutterheads. The front thrust is transmitted to the front chest shell via the cutterheads, force-transferring ring or bearing, etc. The load path of the thrust from the tunnel face to the chest shell is shown in Figure 4. 


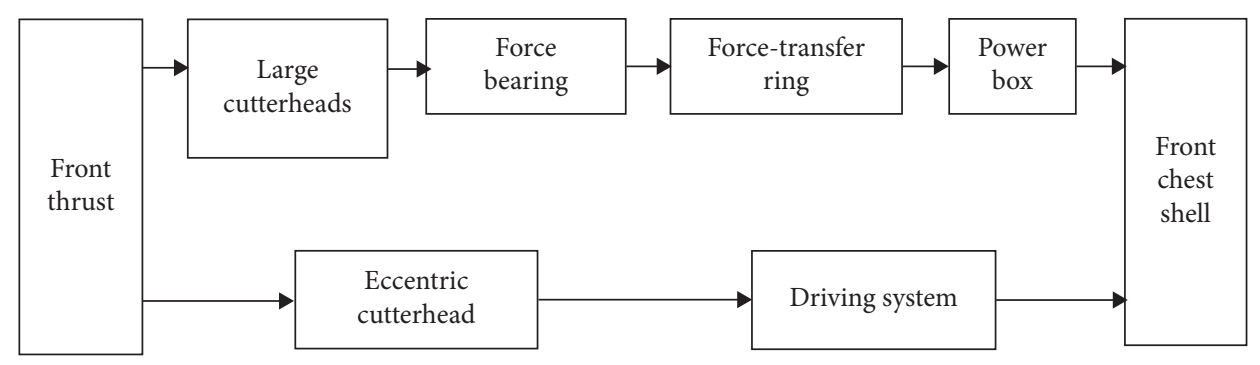

FIgURE 4: Transmission of front thrust.

For the special-shaped full-section shield machine, the thrust from the cylinder is the sum of all the resistant forces during its advancing propulsion. It is assumed that the soil in the soil tank is in a uniformly pressurized state and in good flow plasticity during the working process. Neglecting some small parts of the resistant forces, the jacking thrust in an ideal condition can be defined as follows:

$$
F=F_{1}+F_{2}+F_{3} \text {. }
$$

2.4. Analytical Model of Cutterhead Thrust. The cross-sectional shape of this quasirectangular shield is shown in Figure 5. The variable symbols and corresponding geometric dimensions are shown in Table 1.

Based on Figure 5 and Table 1 and for the simplicity of calculation, the cross section of this quasirectangular shield is simplified into a combination of a rectangle and two semicircles.

Compared with the actual geometry of the quasirectangular shield, the simplified geometry has a deviation of $1.4 \%$ for the front excavation area and $1.1 \%$ for the outer surface. These deviations seem to be very small, and thus, the model can be employed for the analysis.

Figure 6 shows the simplified cross section of the shield. The frontal resistance is defined as follows:

$$
\begin{aligned}
F_{1}= & \int_{0}^{2 \pi} \int_{0}^{(D / 2)} K \gamma(H-r \sin \alpha) r \mathrm{~d} r \mathrm{~d} \alpha \\
& +\int_{0}^{d} \int_{H-(D / 2)}^{H+(D / 2)} \mathrm{d} l \mathrm{~d} h=\left(\frac{\pi D^{2}}{4}+\mathrm{d} D\right) \cdot K \gamma H,
\end{aligned}
$$

where $K$ is the coefficient of lateral earth pressure, $\gamma$ is the bulk density $\left(\mathrm{kN} / \mathrm{m}^{3}\right), H$ is the depth of burial $(\mathrm{m}), D$ is the diameter of shield excavation (m), and $d$ is the width of the simplified rectangle section $(\mathrm{m})$.

The surface friction of the shield is estimated by using the friction coefficient and the pressure imposed on the shell surface. The earth pressure imposed on the shell surface of the shield is composed of two parts: one is the earth resistance to the soil and the other is the shield self-weights. The schematic diagram of earth pressure distribution is shown in Figure 7. Figure 7(a) shows the earth pressure generated by the self-weight of soil. Figure 7(b) shows the soil resistance of shield self-weight. Figure 7(c) shows the sum of them, that is, the total earth pressure on the shell surface of the shield.

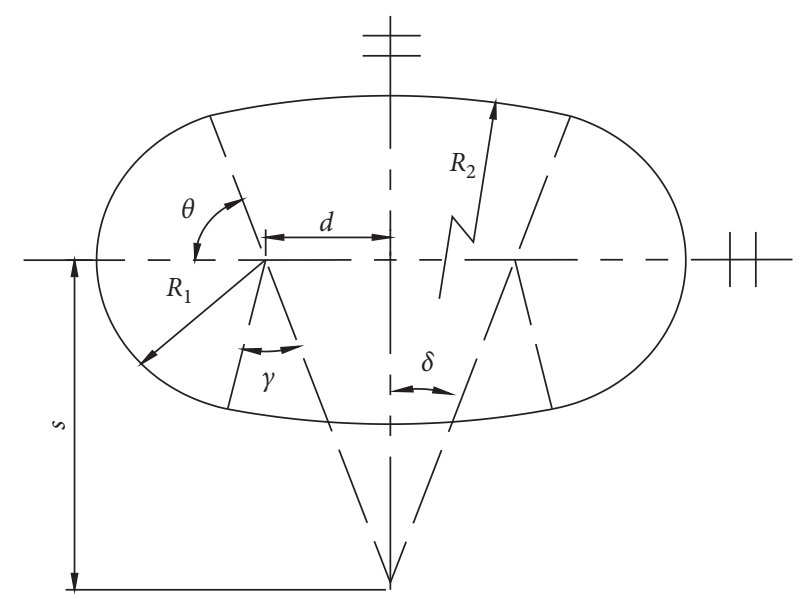

FIGURE 5: Cross-sectional shape of quasirectangular shield.

Except for the self-weight of the shield, the soil reaction force below the shield is equal to the one above the shield. Based on the theory of soil mechanics, the lateral earth pressure at one point in the soil is equal to the vertical earth pressure at that point multiplied by the coefficient of lateral earth pressure. Therefore, the vertical earth pressure and the lateral earth pressure at points A and B in Figure 6 are equal. In this condition, the vertical earth pressure is symmetrical, and the lateral earth pressure is bilaterally symmetric, as shown in Figure 7(a).

In Figure 8, the vertical earth pressure pressed on the unit length of the shield shell is defined as follows:

$$
\begin{aligned}
N_{1} & =\int d N_{1}=\int d N_{1}^{\prime} \cdot \sin \alpha \\
& =\int_{0}^{2 \pi} \gamma\left(H-\frac{D}{2} \sin \alpha\right) \cdot \sin \alpha \cdot \frac{D}{2} \mathrm{~d} \alpha \\
& =2 \gamma D H-\frac{\pi}{4} \gamma D^{2}, \\
N_{2} & =\gamma d\left(H-\frac{D}{2}\right) .
\end{aligned}
$$

Similarly, the lateral earth pressure imposed on the unit length of the shell is shown in Figure 9, which is defined as follows:

$$
N_{3}=2 \gamma K_{a} D H-\frac{1}{2} \gamma K_{a} D^{2},
$$


TABLE 1: Geometric parameters of quasirectangular shield.

\begin{tabular}{lccccccccc}
\hline Width $(\mathrm{m})$ & Height $(\mathrm{m})$ & Length $(\mathrm{m})$ & $R_{1}(\mathrm{~m})$ & $R_{2}(\mathrm{~m})$ & $\mathrm{D}(\mathrm{m})$ & $S(\mathrm{~m})$ & $\theta\left(^{\circ}\right)$ & $\Delta\left({ }^{\circ}\right)$ & $\zeta\left(^{\circ}\right)$ \\
\hline 11.83 & 7.26 & 11.61 & 3.37 & 15.61 & 2.55 & 11.97 & 78 & 12 & 24 \\
\hline
\end{tabular}

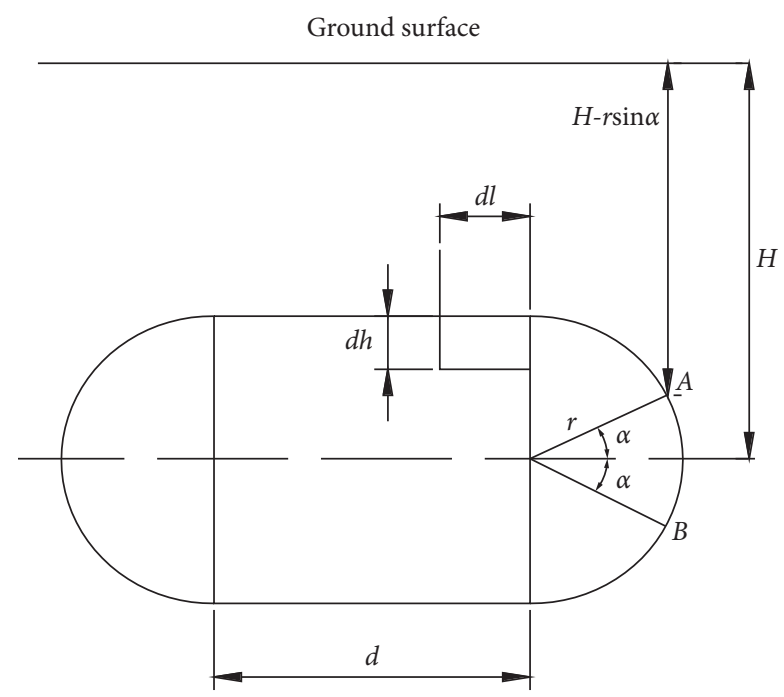

FIGURE 6: Simplified cross section of shield machine.
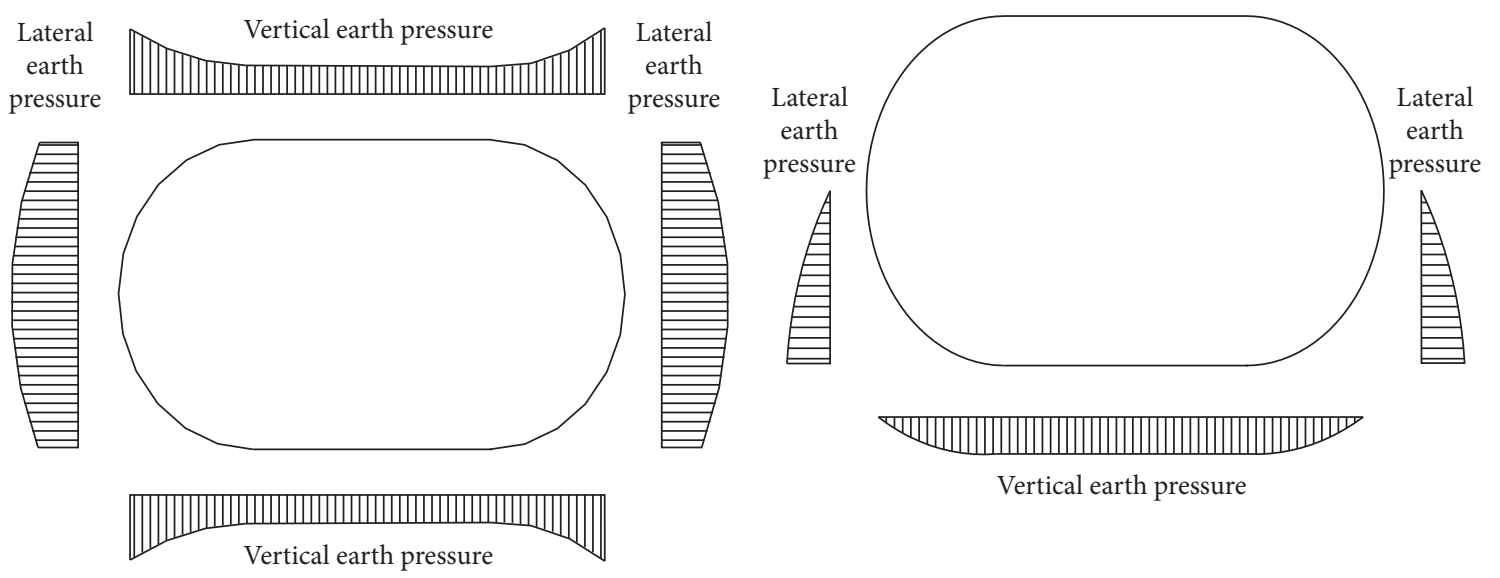

(a)

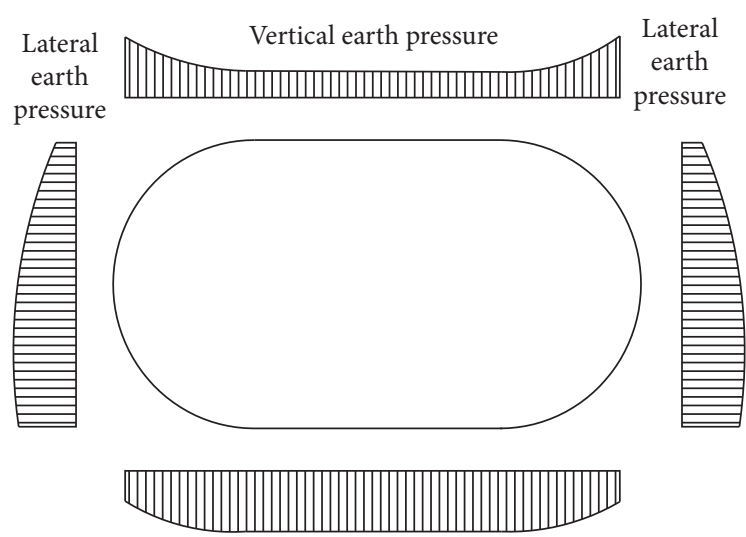

Vertical earth pressure

(c)

FIGURE 7: Earth pressure imposed on the surface of shield shell. 


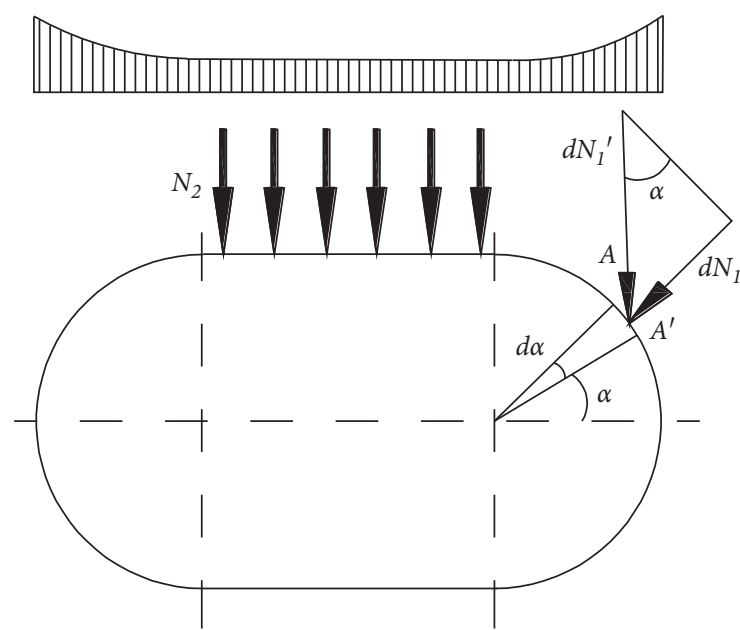

Figure 8: Vertical earth pressure.

where $K_{a}$ is the coefficient of active earth pressure.

Based on Equations (3), (4), and (5), the friction between the surrounding soil layer and the shield shell is defined as follows:

$$
\begin{aligned}
F_{2} & =f L\left(N_{1}+N_{2}+N_{3}\right) \\
& =f \gamma L\left(2 D H-\frac{\pi D^{2}}{4}+\mathrm{d} H-\frac{1}{2} d D+2 K_{a} D H-\frac{1}{2} K_{a} D^{2}\right),
\end{aligned}
$$

where $f$ is the friction coefficient between shell and soil and $L$ is the contact length of soil and shell.

The resultant of the positive pressure imposed on the lower surface of the shield shell is equal to the shield's selfweight. Therefore, the friction generated by the shield selfweight can be calculated as follows:

$$
F_{3}=f L w .
$$

The total thrust of the shield can be obtained by substituting $F_{1}, F_{2}$, and $F_{3}$ into (1), as follows:

$$
\begin{aligned}
F & =K \gamma H\left(\frac{\pi D^{2}}{4}+\mathrm{d} D\right)+f w L \\
& =f \gamma L\left(2 D H-\frac{\pi D^{2}}{4}+\mathrm{d} H-\frac{1}{2} d D+2 K_{a} D H-\frac{1}{2} K_{a} D^{2}\right) .
\end{aligned}
$$

\section{Thrust Simulation of Cutterheads}

3.1. Establishment of the Cutterhead Model. The technical parameters of the quasirectangular shield investigated herein are shown in Table 2. However, due to the complexity of the shield structure, some parts have to be simplified. For example, the components without bearing thrust are removed, and some local constituents such as scrapers, small holes, and chamfer are ignored. In addition, the shape of the

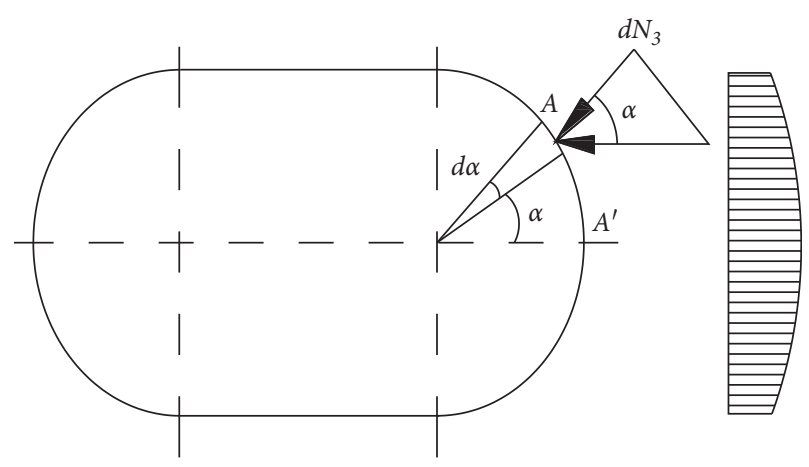

Figure 9: Lateral earth pressure.

TABLE 2: Technical parameters of the quasirectangular shield.

\begin{tabular}{lc}
\hline Technical parameters & Value \\
\hline Cutting diameter of large cutterhead $(\mathrm{mm})$ & 6730 \\
Rated torque of large cutterhead $(\mathrm{kN} \cdot \mathrm{m})$ & 4448 \\
Rotating speed of large cutterhead $(\mathrm{r} / \mathrm{min})$ & $0-1$ \\
Rated torque of eccentric cutterhead $(\mathrm{kN} \cdot \mathrm{m})$ & 440 \\
Rotating speed of eccentric cutterhead $(\mathrm{r} / \mathrm{min})$ & $0-2.2$ \\
Maximum propulsion velocity $(\mathrm{mm} / \mathrm{min})$ & 60 \\
\hline
\end{tabular}

front-end face is also simplified. Figure 10 shows the simplified model employed in the simulation.

3.2. Parameter Setting. Physical and mechanical parameters of the simulation for soil, cutterheads, and their interaction are given in Table 3, which are obtained based on the materials from the cutterheads and the soil information in the construction site.

3.3. Setting of Cutterheads Rotation Velocity and Propulsion Velocity. Different propulsion velocities and cutterhead velocities are set for different working conditions. Based on the mechanics laws in the contact between cutterheads and soil, the influencing factors in the system of soil and shield are analyzed, and the correlation between cutters and surrounding soil is also analyzed by the simulation to determine the values of the cutting parameter and soil deformation. Velocity settings of the cutterheads are shown in Table 4.

3.4. Mesh Generation. The simplified geometric model of shield and material properties are imported into ANASY Workbench. 3D 20-node hexahedral mesh is used to mesh every component involved in the model to improve calculation accuracy. Due to the large size of the front shell, the smallest element size is set as $60 \mathrm{~mm}$. The number of grid cells is 399558 , and the number of nodes is 1560839 . The divided model is shown in Figure 11.

3.5. Boundary Conditions. The following assumptions are made to simplify the finite element analysis: (1) the soil is a uniform, linear isotropic elastomer material; (2) uniform force is imposed on the surface of single cutterhead; and (3) 


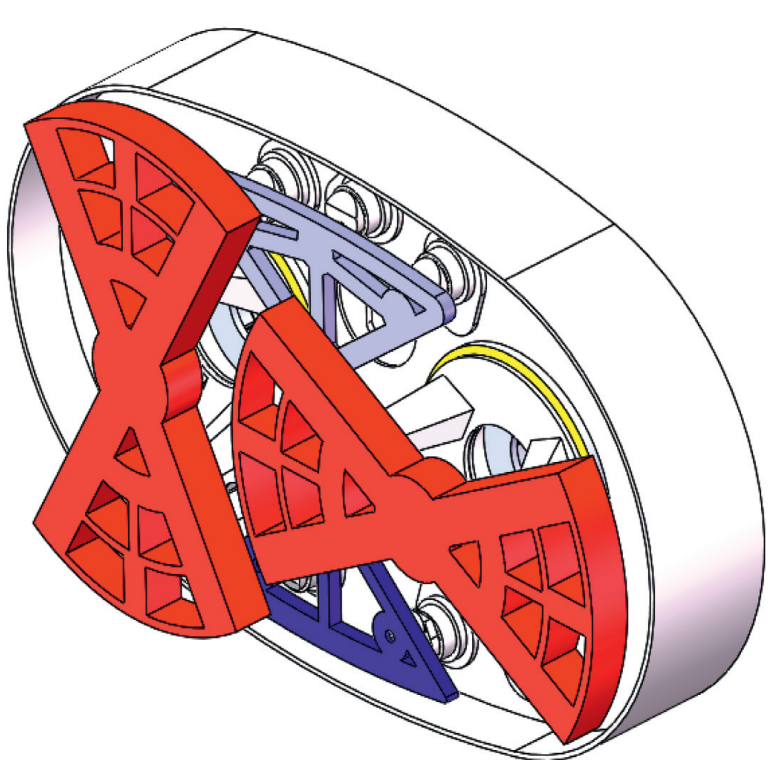

Figure 10: Simplified model of cutterheads.

TABLE 3: Material parameters used in simulation.

\begin{tabular}{lcc}
\hline Item & Property parameter & Value \\
\hline \multirow{3}{*}{ Soil } & Poisson ratio & 0.35 \\
& Elastic modulus $(\mathrm{Pa})$ & $1.09 \times 10^{7}$ \\
& Density $\left(\mathrm{kg} \cdot \mathrm{m}^{-3}\right)$ & 1700 \\
\hline \multirow{3}{*}{ Cutterhead } & Poisson ratio & 0.28 \\
& Elastic modulus $(\mathrm{Pa})$ & $2.06 \times 10^{11}$ \\
& Density $\left(\mathrm{kg} \cdot \mathrm{m}^{-3}\right)$ & 7850 \\
\hline \multirow{3}{*}{ Soil-soil } & Restitution coefficient & 0.20 \\
& Static friction coefficient & 0.25 \\
& Dynamic friction coefficient & 0.04 \\
Soil-cutterhead & Restitution coefficient & 0.10 \\
& Static friction coefficient & 0.20 \\
& Dynamic friction coefficient & 0.02 \\
\hline
\end{tabular}

TABLE 4: Velocity settings of cutterhead.

\begin{tabular}{lc}
\hline Rotating speed of large cutter $(\mathrm{r} / \mathrm{min})$ & $\begin{array}{c}\text { Propulsion speed } \\
(\mathrm{mm} / \mathrm{min})\end{array}$ \\
\hline \multirow{2}{*}{0.8} & 10 \\
& 20 \\
& 30 \\
\hline \multirow{3}{*}{1.0} & 10 \\
& 20 \\
1.2 & 30 \\
\hline
\end{tabular}

the shield propulsion is along a straight line in the normal soft soil, regardless of deflection.

The formula for calculating the front thrust of the earth pressure balance shield is defined as follows:

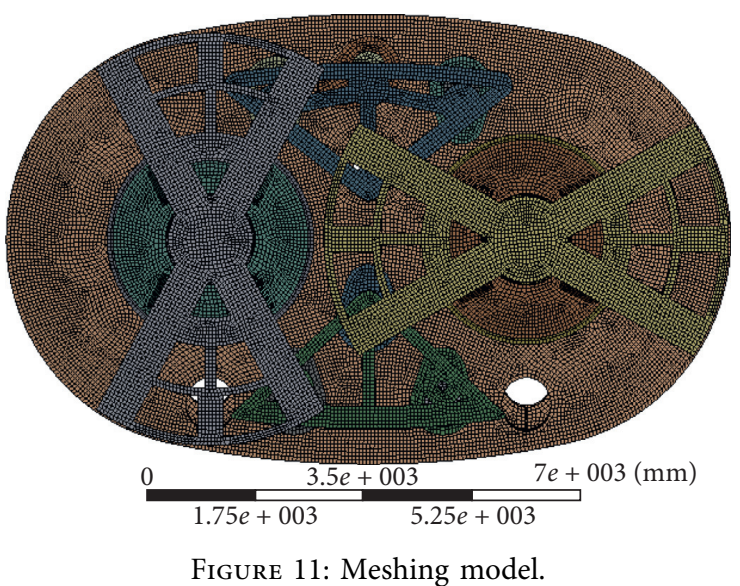

$$
F=\frac{\pi D^{2}}{4} K \gamma H
$$

where $K$ is the coefficient of lateral soil pressure, $\gamma$ is the bulk density, $H$ is the buried depth of the shield axis, and $D$ is the excavation diameter of the shield.

Since the front thrust is proportional to the area of the cutterhead, the thrust of each cutterhead is calculated and the corresponding results are shown in Table 5.

According to the results shown in Table 5, corresponding loads are imposed on each cutterhead. In actual working conditions, the shell is subjected to the reaction force and earth pressure and the shell end is connected to the main body of the propulsion system. Hence, the surrounding of the shell is treated as the fixed constraint. The model after the boundary conditions are applied is shown in Figure 12.

3.6. Simulation Result and Discussion. Compared with the shield performance and data obtained from on-site tests, the equivalent stress and deformation of the finite element analysis model are evaluated. Figure 13 shows the equivalent stress and deformation nephograms of the front shell chest in the working condition.

According to Figure 13(a), the stress distribution on the chest plate is nearly uniform, and the stress value in most regions is between $5 \mathrm{MPa}$ and $45 \mathrm{MPa}$. The maximum stress is found at the joint between the shell and the lower and middle parts of the rib, and its value is $208.44 \mathrm{MPa}$, which is generated due to the stress concentration induced by local structural change. The material of the shell is Q345 B with a yield stress of $345 \mathrm{MPa}$. This stress level is below the yield limit. Furthermore, the joint is welded in the actual manufacturing process to effectively strengthen structural stiffness and strength, so it is in a safe elastic range. According to Figure 13(b), the maximum deformation of the chest plate is found in the center area, and its value is $1.9984 \mathrm{~mm}$ which is rather small and meets the design requirement.

Based on the simulation results, the total thrust of the cutterhead is proportional to the stress of each measuring point on the chest plate. Taking points A and B in Figure 13 as example, the corresponding relationship between the total 
TABLE 5: Calculated thrust for each cutterhead.

Object

Single large cutterhead

Upper eccentric cutterhead

Lower eccentric cutterhead

Total combined cutterhead
Thrust $(\mathrm{kN})$

8038

2280

2850

21206

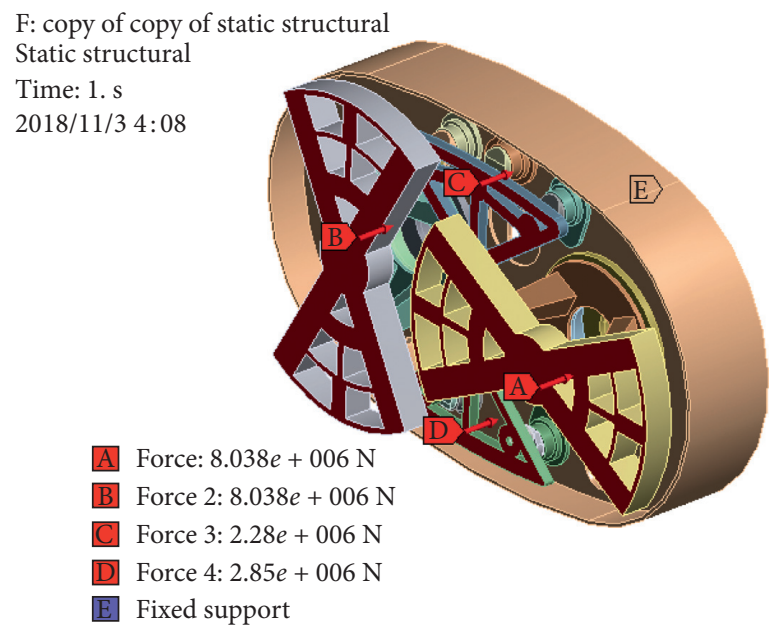

Figure 12: Boundary condition setting.

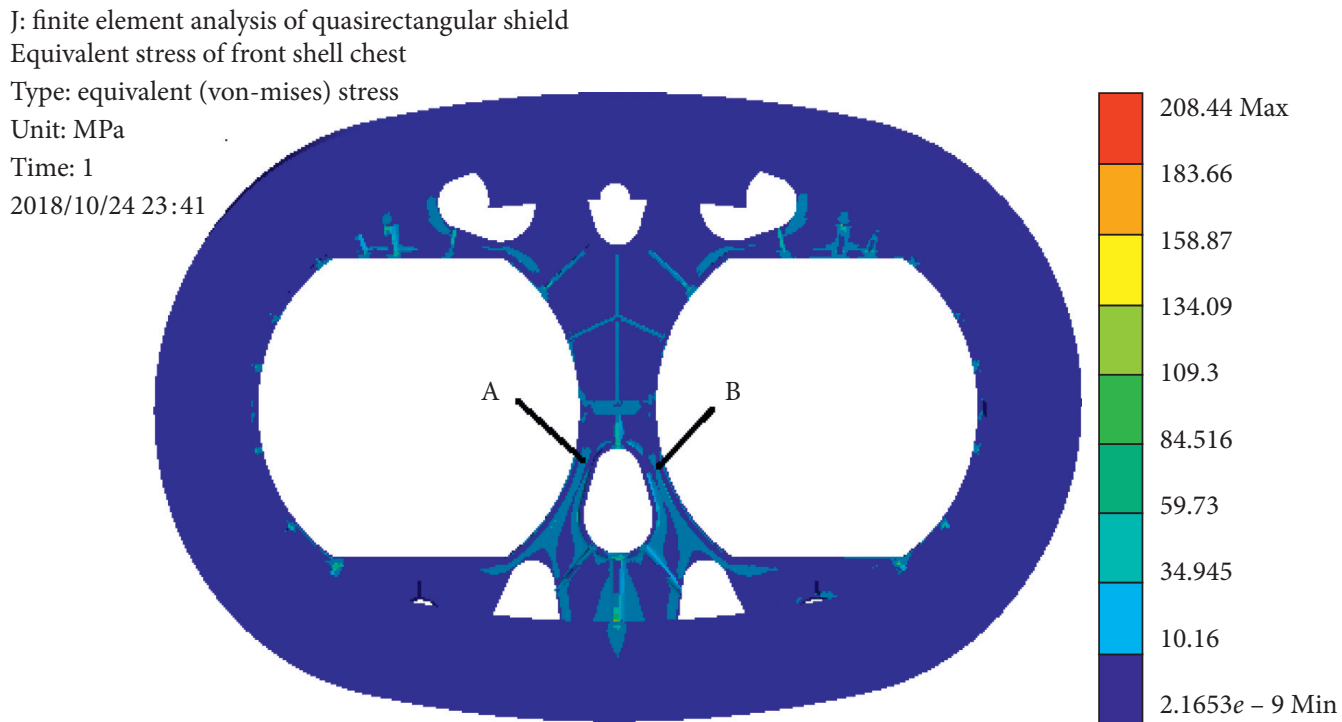

(a)

Figure 13: Continued. 
J: finite element analysis of quasirectangular shield

Deformation of front shell chest

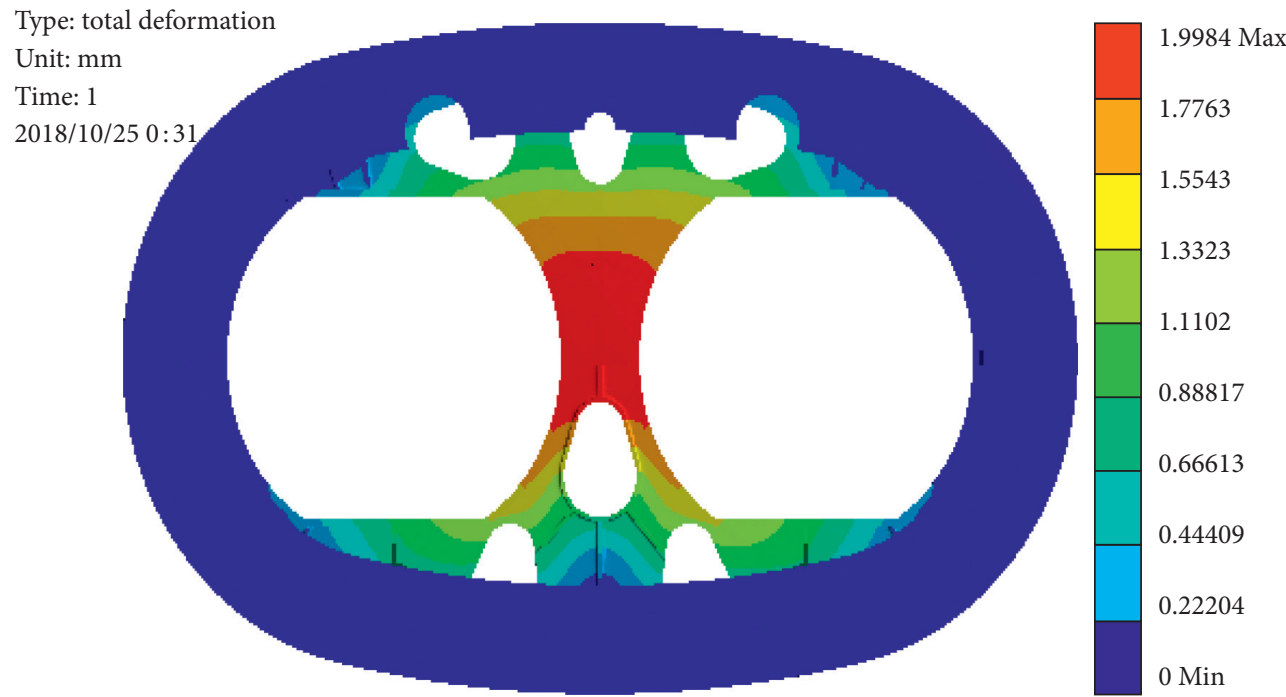

(b)

FIGURE 13: Finite element result. (a) Equivalent stress nephogram. (b) Total deformation nephogram.

thrust and the measuring equivalent stress is shown in Figure 14. The stress at the measuring point changes obviously and corresponds to the thrust. Therefore, the thrust can be estimated by the measuring stress.

\section{Monitoring Experiment of Cutterhead Thrust}

Cutterhead system is a key component of the quasirectangular shield. The force condition of it is very complicated when it is operated during a construction process. Due to the limitation of the construction environment and monitoring conditions, direct measurement of the force condition of cutterheads is very difficult.

4.1. Measuring Point. Based on the finite element analysis and on-site excavation environment, eight measuring points are finally determined, which are shown in Figure 15. There are two points located at the large cutterhead drivers, corresponding to points A and B shown in Figure 13. The other six points are located near the eccentric cutterhead driver.

Considering the limitations of the environment and the unknown direction of principal stresses, three-axis $45^{\circ}$ strain rosette gauges are used in order to reduce interference during working operation, as shown in Figure 16.

4.2. Experimental Conditions. The actual thrust of the shield has a great relationship with actual geological conditions. Figure 17 shows the geologic aspects of the construction site when the shield is in operation. The measuring period is shown in Figure 18.

The earth pressure in the shield is approached by using the concept of dynamic balance, so the friction imposed on the shell of the soil layer, $F_{2}$, and the friction of the shield self-weight, $F_{3}$, can be approximately treated to be

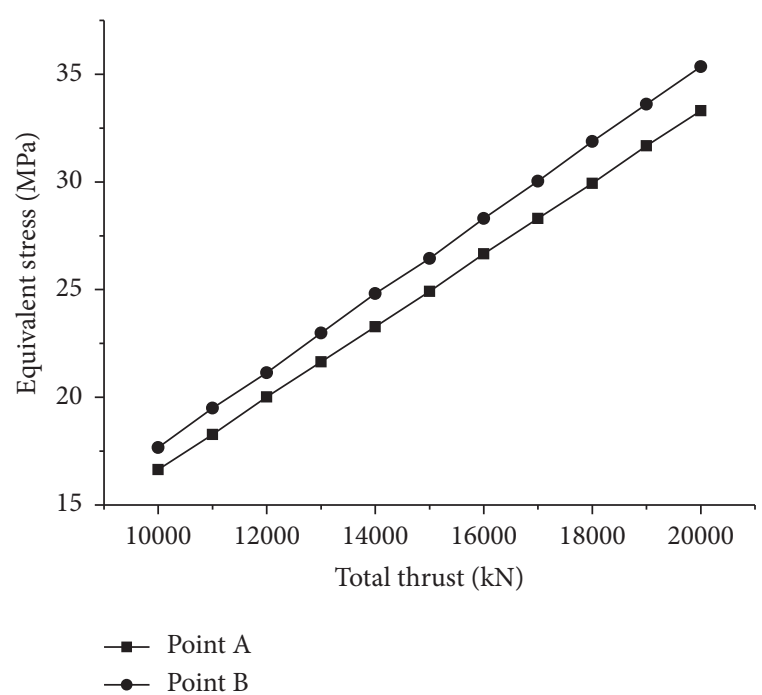

FIGURE 14: Correspondence between equivalent stress and front total thrust.

unchanged in the propulsion process while monitoring system is collecting data. Therefore, the stress change can be eliminated when the balance is cleared. The collected data are the stress change from the shield frontal resistance, $F_{1}$, in the propulsion process.

4.3. Analysis of Experimental Results. The strain state of each key position in the construction process is obtained. The load distribution of cutterheads is calculated, and the axial load change of each cutterhead during the propulsion process is also obtained.

The strain curve collected by the channels of the measuring point 8 on the chest plate within one minute is shown in Figure 19. It can be seen from the figure that all strains 


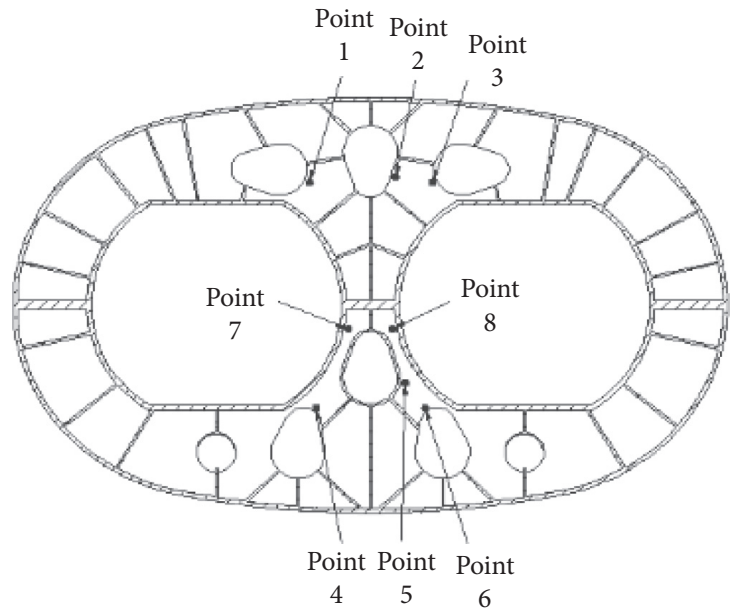

FIGURE 15: Distribution of measuring points.

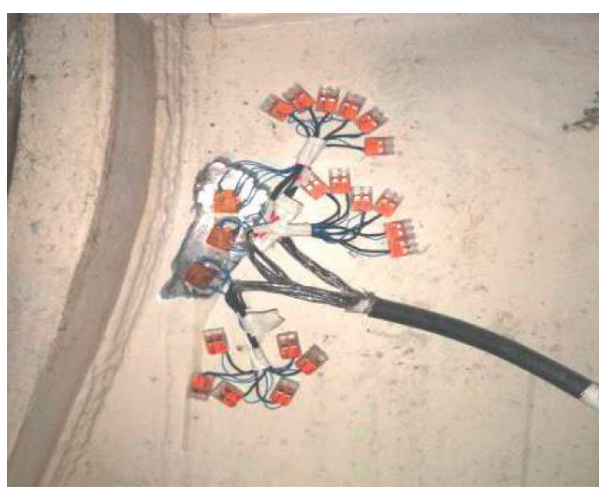

FIGURE 16: Strain rosette of measuring point.

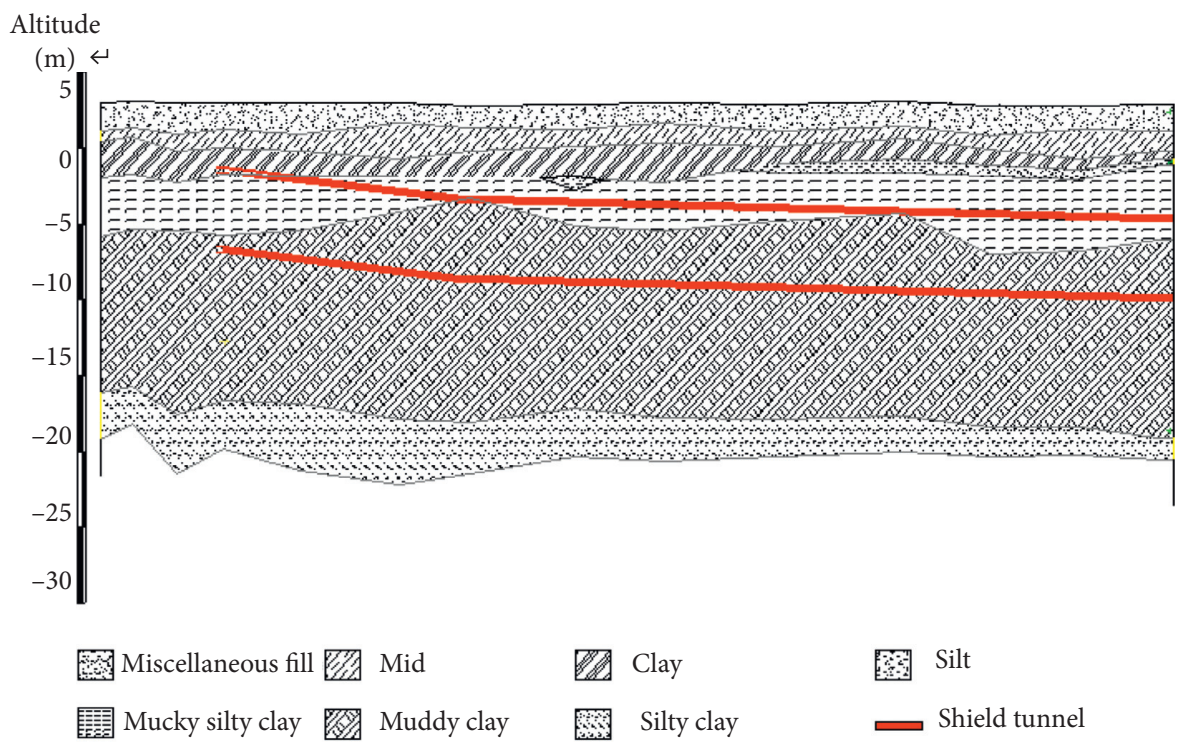

Figure 17: Geologic aspects. 


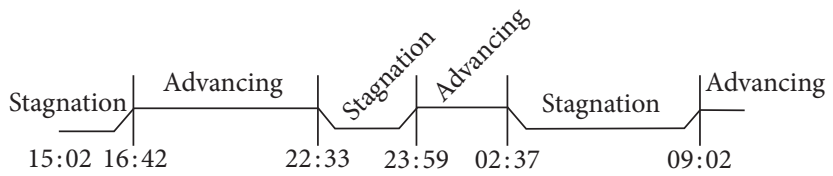

FIgURe 18: Measuring period.

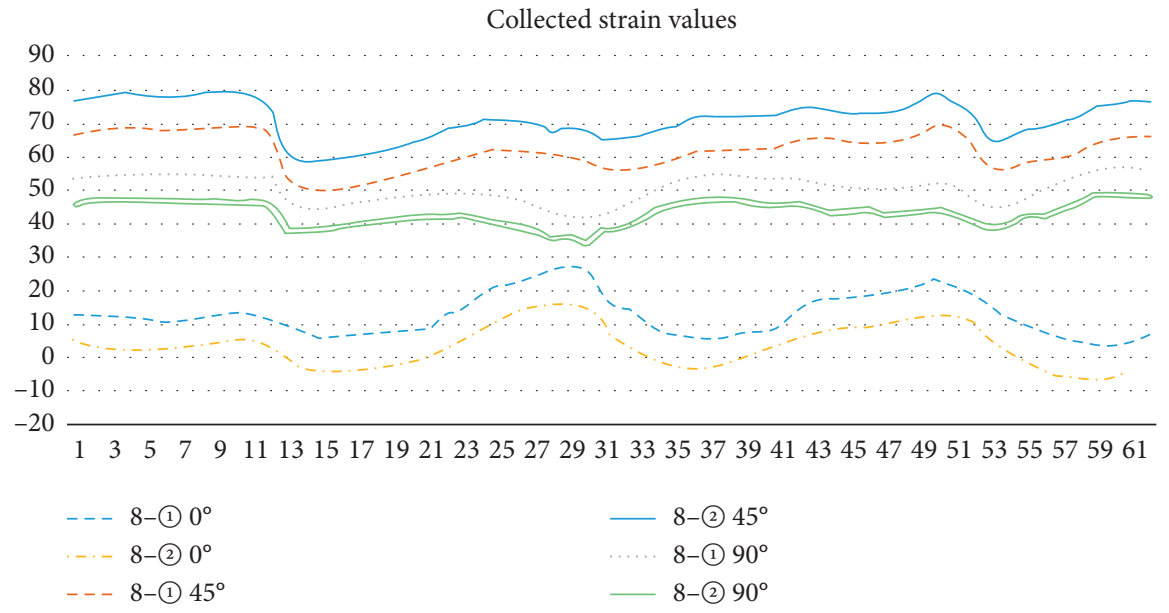

FIGURE 19: Collected strain curves.

have the same change trend and the same periodic change with the rotation angle of cutterheads.

\section{Calculation of Stresses on the Chest Plate}

The principal stresses $\sigma_{1}$ and $\sigma_{2}$ are calculated from the collected strains by using the following formula:

$$
\left.\begin{array}{c}
\sigma_{1} \\
\sigma_{2}
\end{array}\right\}=\frac{E}{1-\mu^{2}}\left[\begin{array}{c}
\frac{1+\mu}{2}\left(\varepsilon_{0}+\varepsilon_{90}\right) \\
\pm \frac{1-\mu}{\sqrt{2}} \sqrt{\left(\varepsilon_{0}-\varepsilon_{45}\right)^{2}+\left(\varepsilon_{45}-\varepsilon_{90}\right)^{2}}
\end{array}\right] .
$$

The stress perpendicular to the $\sigma_{1}-\sigma_{2}$ stress plane is assumed to be zero since the value of it is very small when compared with $\sigma_{1}$ and $\sigma_{2}$. According to the von Mises strength theory, the equivalent stress can be calculated as follows:

$$
\sigma=\frac{\sqrt{2}}{2} \sqrt{\left(\sigma_{1}-\sigma_{2}\right)^{2}+\left(\sigma_{2}-\sigma_{3}\right)^{2}+\left(\sigma_{3}-\sigma_{1}\right)^{2}} .
$$

The equivalent stress calculated from (11) for the measuring point 8 within one minute is taken herein, as an example. Three sets of data from the same measuring point are mutually verified. The average value after discarding the abnormal data is taken as the final equivalent stress of the measuring point.

The variation curve of the equivalent stress from point 8 during the whole experiment after taking average value is shown in Figure 20. The equivalent stress that varies from

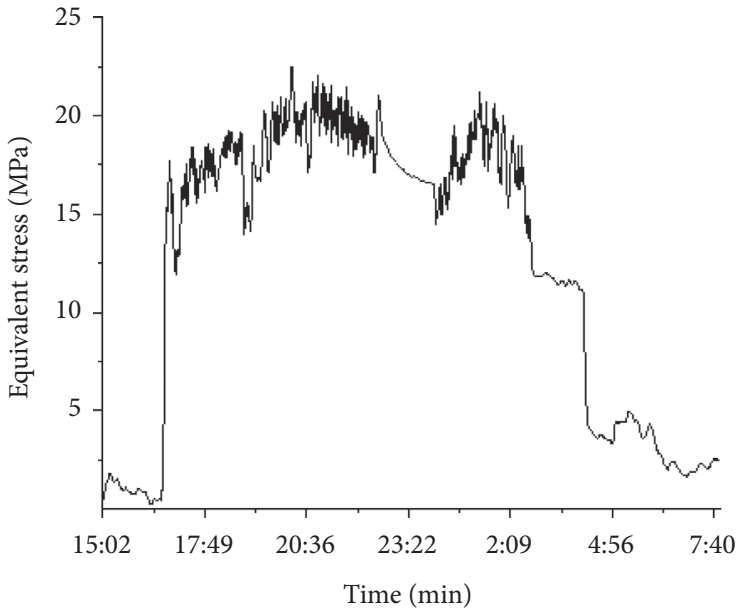

Figure 20: Equivalent stress curve of point 8.

measuring points at different stages is obvious. The change trend is the same as one of the system jacking thrusts.

The equivalent stress curve of the measuring point for a period of time is drawn in Figure 21. Wave peaks and valleys change in a cycle of $50 \mathrm{~s}$. The velocity of large cutterheads is $1.2 \mathrm{r} / \mathrm{min}$ in this period. Therefore, the stress fluctuation period of the measuring point is consistent with the rotation period of the cutterhead.

\section{Total Thrust of Cutterhead}

Based on the period relationship discussed above, one cycle of $50 \mathrm{~s}$ is selected to obtain the average value of the thrust. 


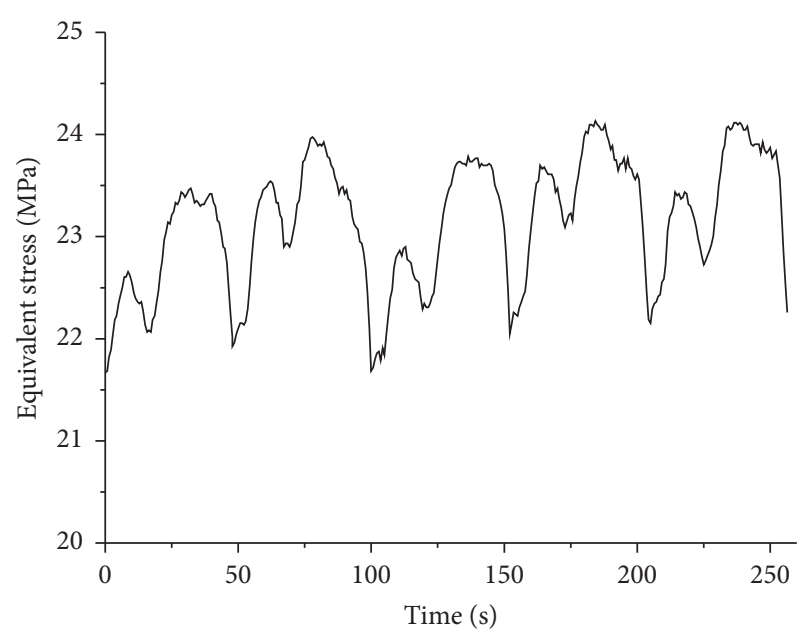

Figure 21: Local equivalent stress curve.

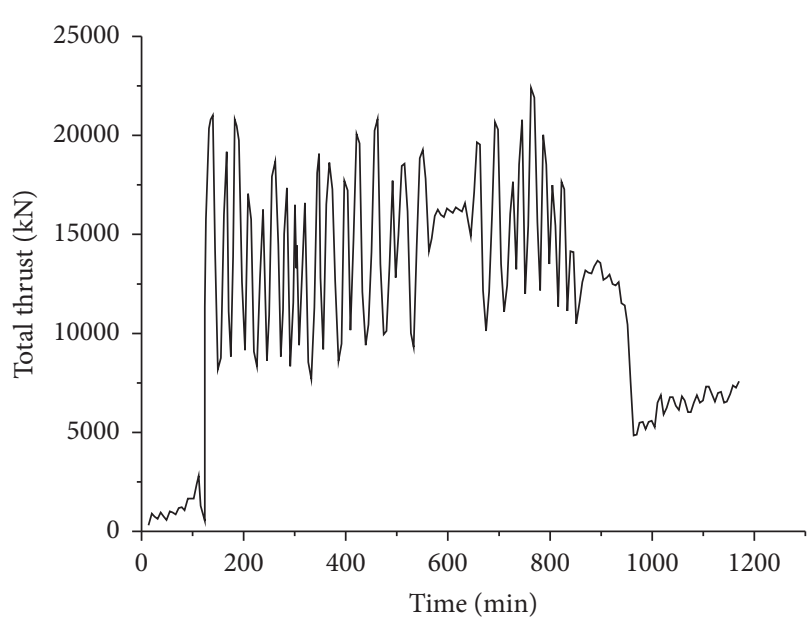

Figure 22: Total thrust variation curve.

The calculated equivalent stress is substituted into the stressthrust relationship. The total front thrust variation curve in the actual working process is obtained by using the interpolation method, as shown in Figure 22. The calculated total thrust change is consistent with the actual experimental conditions recorded. The correctness of calculated results thus is verified.

According to literature studies and the experience of shield construction in China and abroad, the front resistance of shield is about $27 \%$ to $50 \%$ of the total thrust. The specific value of the front resistance is fluctuant and cannot be determined on-site. However, the range of the total thrust can be obtained based on the total thrust of the system. The calculated data and the measured data from the monitoring system during a local period are compared, as shown in Figure 23. It is known that actual thrust is all within this range and the calculated data seem to be reasonable.

\section{Thrust Distribution of Each Cutterhead}

Compared with the experimental data of the same period, the thrust of the upper eccentric cutterhead is less than that

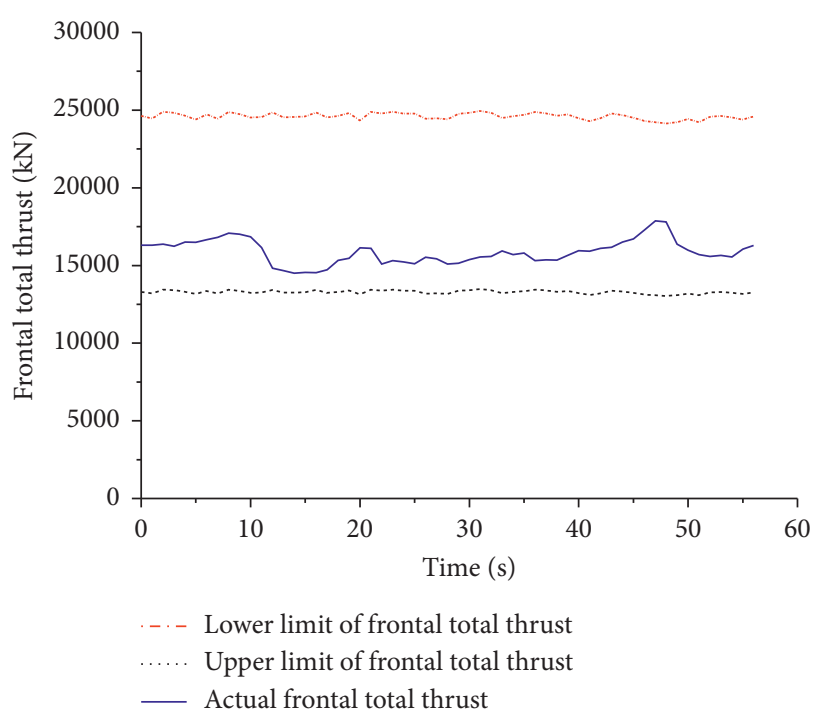

Figure 23: Total thrust variation curve.

TABLE 6: Thrust ratios at corresponding measuring points.

\begin{tabular}{lccc}
\hline $\begin{array}{l}\text { Point 4/ } \\
\text { point 1 }\end{array}$ & $\begin{array}{c}\text { Point 5/ } \\
\text { point 2 }\end{array}$ & $\begin{array}{c}\text { Point 6/ } \\
\text { point 3 }\end{array}$ & $\begin{array}{r}\text { Sum of points 4, 5, 6/sum } \\
\text { of points } 1,2,3\end{array}$ \\
\hline 1.93 & 2.16 & 1.23 & 1.81 \\
\hline
\end{tabular}

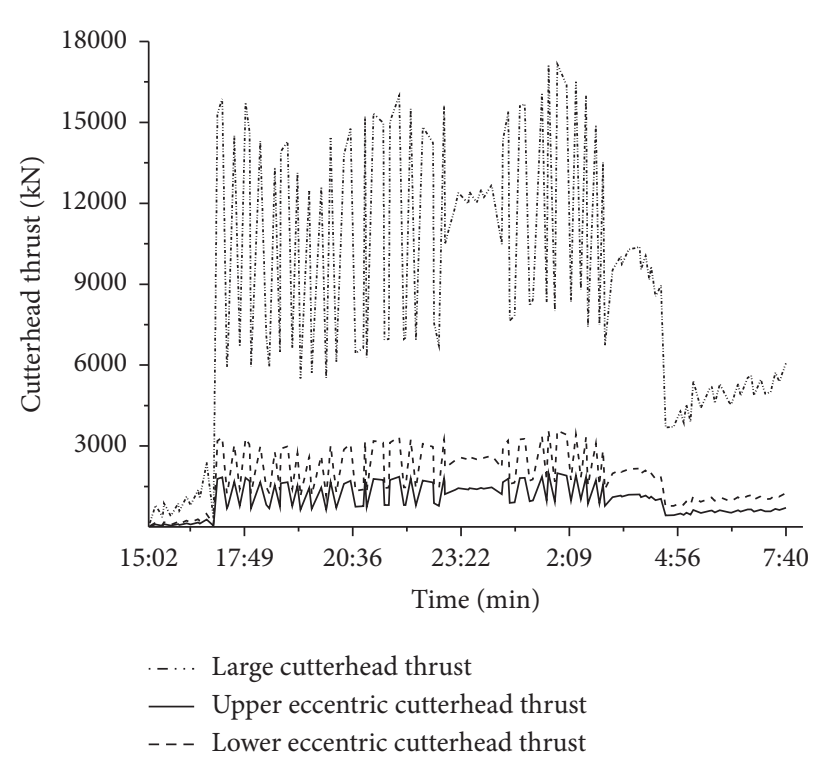

FIGURE 24: Total thrust variation curve.

of the lower eccentric cutterhead. Based on the distribution of measuring points, points 4,5 , and 6 located in the lower eccentric cutterhead are, respectively, corresponding to the points 1, 2, and 3 located in the upper eccentric cutterhead. The thrust ratios of these points are calculated and are shown in Table 6.

In the experimental data, the thrust (stress) at the lower eccentric cutterhead is about 1.8 times that at the upper eccentric cutterhead. 
The thrust ratio and corresponding relationship between the total thrust and the large cutterhead thrust are concluded. Based on the measured data from the monitoring system, the thrusts of each cutterhead in the experimental period can be calculated. These thrusts are shown in Figure 24, where the large cutterhead thrust is the resultant force of the left and right large cutterheads.

\section{Conclusion}

This paper studies the characteristics and performance of cutterheads in the quasirectangular shield. The stress nephogram and force nephogram of cutterheads in the working condition have been obtained and analyzed. The maximum stress and displacement of cutterheads meet the design requirement. Meanwhile, the equivalent stress is linearly related to the propulsion force.

In the construction process, the operation data of key points are obtained by on-site measurement. The total thrust and the thrust distribution of each cutterhead are calculated based on the equivalent stresses at measuring points.

This paper provides a reference for the structural design of shield cutterhead and the evaluation of cutterhead under different working conditions. The thrust stress of shield cutterhead can be derived by the data from on-site measurement. The stress detection system can be used to assess the thrust of the shield and feedback the thrust of the cutterhead in time to ensure the safety of personnel and property during the tunnel construction.

\section{Data Availability}

The data used to support the findings of this study are included within the article.

\section{Conflicts of Interest}

The authors declare that they have no conflicts of interest.

\section{Acknowledgments}

The authors acknowledge the financial supports received from National Natural Science Foundation of China (nos. 11972203 and 11572162), 47th Scientific Research Foundation for Returned Scholars from Ministry of Education of China, the Natural Science Foundation of Zhejiang Province (LY13A020007), Ningbo Rail Transit (JS-00-SG-17003), and K. C. Wong Magna Fund in Ningbo University.

\section{References}

[1] J. Cui and J. D. Nelson, "Underground transport: an overview," Tunnelling and Underground Space Technology, vol. 87, pp. 122-126, 2019.

[2] M. D'Lima and F. Medda, "A new measure of resilience: an application to the London underground transport," Transportation Research Part A, vol. 81, pp. 35-46, 2015.

[3] J. Zhao and O. Künzli, "An introduction to connectivity concept and an example of physical connectivity evaluation for underground space," Tunnelling and Underground Space Technology, vol. 55, pp. 205-213, 2016.
[4] M. Son and E. J. Cording, "Ground-liner interaction in rock tunneling," Tunnelling and Underground Space Technology, vol. 22, no. 1, pp. 1-9, 2007.

[5] Y. Jin, "Present status and technology of shield tunneling method in Japan," Tunnelling and Underground Space Technology, vol. 18, no. 2-3, pp. 145-159, 2003.

[6] M. D. Han, Z. X. Cai, C. Y. Qu, and L. S. Jin, "Dynamic numerical simulation of cutterhead loads in TBM tunnelling," Tunnelling and Underground Space Technology, vol. 70, no. 8, pp. 286-298, 2017.

[7] Q. Zhang, Z. Hou, G. Huang, Z. Cai, and Y. Kang, "Mechanical characterization of the load distribution on the cutterhead-ground interface of shield tunneling machines," Tunnelling and Underground Space Technology, vol. 47, pp. 106-113, 2015.

[8] C. Balci, "Correlation of rock cutting tests with field performance of a TBM in a highly fractured rock formation: a case study in Kozyatagi-Kadikoy metro tunnel," Tunnelling and Underground Space Technology, vol. 24, no. 2, pp. 423435, 2009.

[9] F. Dahl, E. Grøv, and T. Breivik, "Development of a new direct test method for estimating cutter life, based on the Sievers' J miniature drill test," Tunnelling and Underground Space Technology, vol. 22, no. 1, pp. 106-116, 2007.

[10] J. Liu, M. He, and Z. Song, "Mechanical behaviors of shield tunnel segments due to construction of connecting passages," Chinese Journal of Geotechnical Engineering, vol. 35, no. 2, pp. 271-275, 2013.

[11] H. Li and E. Du, "Simulation of rock fragmentation induced by a tunnel boring machine disk cutter," Advances in Mechanical Engineering, vol. 8, pp. 1-11, 2016.

[12] Q. Geng, H. Zhang, X. Liu, and X. Wang, "Numerical study on the rock muck transfer process of TBM cutterhead with clump strategy based on discrete element method," Tunnelling and Underground Space Technology, vol. 91, Article ID 103000, 2019.

[13] N. Xiao, X.-P. Zhou, and Q.-M. Gong, "The modelling of rock breakage process by TBM rolling cutters using 3D FEM-SPH coupled method," Tunnelling and Underground Space Technology, vol. 61, pp. 90-103, 2017.

[14] M. Entacher, G. Winter, and R. Galler, "Cutter force measurement on tunnel boring machines - implementation at Koralm tunnel," Tunnelling and Underground Space Technology, vol. 38, pp. 487-496, 2013.

[15] H. Ma, L. Yin, and H. Ji, "Numerical study of the effect of confining stress on rock fragmentation by TBM cutters," International Journal of Rock Mechanics and Mining Sciences, vol. 48, no. 6, pp. 1021-1033, 2011.

[16] H. Yang, H. Wang, and X. Zhou, "Analysis on the rock-cutter interaction mechanism during the TBM tunneling process," Rock Mechanics and Rock Engineering, vol. 49, no. 3, pp. 1073-1090, 2015. 